\title{
Cost comparison of linezolid versus vancomycin for treatment of complicated skin and skin-structure infection caused by methicillin-resistant Staphylococcus aureus in Quebec
}

\author{
Martine Pettigrew MSc ${ }^{1}$, Daniel JG Thirion BPharm MSc PharmD FCSHP ${ }^{2}$, \\ Michael Libman $\mathrm{MD}^{3}$, Giovanni Zanotti MSc PharmD ${ }^{4}$
}

\begin{abstract}
M Pettigrew, DJG Thirion, M Libman, G Zanotti. Cost comparison of linezolid versus vancomycin for treatment of complicated skin and skin-structure infection caused by methicillin-resistant Staphylococcus aureus in Quebec. Can J Infect Dis Med Microbiol 2012;23(4):187-195.
\end{abstract}

BACKGROUND: In Canada, complicated skin and skin-structure infection (cSSSI) caused by methicillin-resistant Staphylococcus aureus (MRSA) is usually treated with antibiotics in hospital, with a follow-up course at home for stable patients. The cost implications of using intravenous and oral linezolid instead of intravenous vancomycin in Canadian clinical practice have not been examined.

OBJECTIVES: To evaluate the potential treatment cost impact for the Quebec health care system of linezolid versus vancomycin for MRSA-related cSSSI therapy, using a net impact analysis approach.

METHODS: Health care resource use associated with linezolid and vancomycin therapy was estimated for patients in Quebec, based on expert opinion. Costs were assigned to health care resources (antibiotics, medical supplies, laboratory testing and health care professional time) based on unit prices. The base-case analysis assumed 14 days of antibiotic treatment for both agents; five days in hospital followed by nine days at home. Therapy duration, length of inpatient treatment and discharge rates were varied in sensitivity analyses.

RESULTS: Antibiotic costs were higher for linezolid than for vancomycin, for both inpatient ( $\$ 874$ versus $\$ 144$, respectively) and outpatient therapy ( $\$ 1,356$ versus $\$ 1,242$, respectively). Compared with vancomycin, lower costs for antibiotic preparation, administration and monitoring of linezolid offset drug acquisition costs. Total treatment costs were $\$ 3,850$ for linezolid versus $\$ 5,189$ for vancomycin. Results were sensitive to the number of treatment days spent at home and the discharge rate.

CONCLUSION: Using linezolid instead of vancomycin to treat MRSA-related cSSSI, for hospital and home courses combined, may reduce health care resource utilization and costs in Quebec.

Key Words: Complicated skin and soft-tissue infection; Cost analysis; Linezolid; Methicillin resistance; MRSA; Vancomycin
La comparaison des coûts du linézolid et de la vancomycine pour traiter les infections complexes de la peau et des structures cutanées causées par le Staphylococcus aureus résistant à la méthicilline au Québec

HISTORIQUE : Au Canada, les infections complexes de la peau et des structures cutanées (IcPSC) causées par le Staphylococcus aureus résistant à la méthicilline (SARM) sont généralement traitées à l'aide d'antibiotiques pendant une hospitalisation, suivis d'un traitement à domicile chez les patients stables. Au Canada, on n'a jamais évalué les répercussions financières de l'utilisation du linézolid par voie intraveineuse et par voie orale plutôt que de la vancomycine par voie intraveineuse dans la pratique clinique canadienne. OBJECTIFS : Évaluer les répercussions financières potentielles du traitement au linézolid plutôt qu'à la vancomycine pour soigner une IcPSC liée au SARM dans le système de santé québécois, au moyen d'une analyse de l'impact net.

MÉTHODOLOGIE : Les chercheurs ont évalué l'utilisation des ressources de santé associée à un traitement au linézolid et à la vancomycine au Québec d'après des opinions d'experts. Les coûts étaient affectés aux ressources de santé (antibiotiques, fournitures médicales, tests de laboratoire et temps consacré par les professionnels de la santé) d'après les prix unitaires. L'analyse du cas de base supposait une antibiothérapie de 14 jours pour chacun des deux médicaments : cinq jours à l'hôpital suivis de neuf jours à domicile. La durée du traitement, la durée du traitement sous hospitalisation et le taux de congé variaient selon les analyses de sensibilité.

RÉSULTATS : Le coût du linézolid était plus élevé que celui de la vancomycine, tant chez les patients hospitalisés ( 874 \$ par rapport à $144 \$$, respectivement) qu'en consultations externes (1 356 \$ par rapport à $1242 \$$, respectivement). Comparativement à la vancomycine, des frais moins élevés de préparation, d'administration et de surveillance du linézolid en compensaient les coûts d'acquisition. Les coûts totaux du traitement au linézolid s'élevaient à 3850 \$, par rapport à 5189 \$ pour la vancomycine. Les résultats étaient sensibles au nombre de jours de traitement passés à domicile et au taux de congé.

CONCLUSION : Au Québec, l'utilisation du linézolid de préférence à la vancomycine pour traiter les IcPSC liées au SARM, que ce soit chez les patients hospitalisés ou à domicile, peut limiter le recours aux ressources de santé et les coûts.

trials (3). Therefore, we used SSSI to clearly define the target population in our study, while retaining whichever term was used by the authors of other studies when discussing their results.

MRSA is now responsible for a high proportion of SSTIs in Canada, for example, the prevalence of MRSA was 19\% among 299 patients with S aureus-positive SSTIs who presented to seven emergency departments in the Greater Toronto (Ontario) Area between March and June, 2007 (4), and 17\% among 205 patients with SSTIs who presented to an emergency department in London, generic classification while SSSI is a well-defined term used in clinical

${ }^{1}$ Symbiose Partenariat Stratégique Inc; ${ }^{2} \mathrm{Mc}$ Gill University Health Centre and Faculté de pharmacie, Université de Montréal; ${ }^{3}$ Division of Infectious Diseases, Department of Microbiology, McGill University, Montreal; ${ }^{4}$ Health Economics $\mathcal{E}$ Outcomes Research, Pfizer Canada Inc, Kirkland, Quebec

Correspondence: Ms Martine Pettigrew, Symbiose Partenariat Stratégique Inc, 3915 Rue Saint-Urbain, Montreal, Quebec H2W 1T9.

Telephone 514-286-9115, fax 514-286-9561, e-mail mpettigrew@symbiosemkg.com 


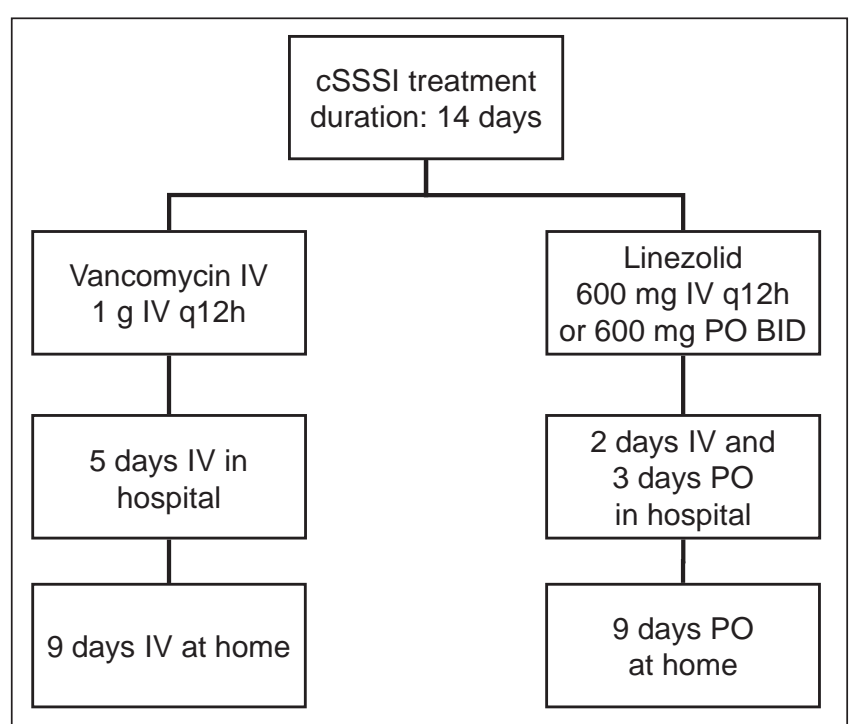

Figure 1) Antibiotic treatment course options in Quebec for complicated skin and skin-structure infection (cSSSI) caused by methicillin-resistant Staphylococcus aureus. BID Twice daily; IV Intravenous; PO Per oral; q12h Every $12 \mathrm{~h}$

Ontario between July and August, 2008 (5). An even higher rate of MRSA infection was reported at an emergency department in Vancouver, British Columbia, with a 55\% period prevalence among 447 patients diagnosed with SSTIs between January 2003 and September 2004, increasing significantly from $21 \%$ in the first month of the study period to $68 \%$ in the final month (6). A more recent study surveying 1353 SSTI cases from 18 hospitals and two community health centres in six provinces from July 2008 to April 2009 found an average MRSA prevalence of $32 \%(7)$. In the present study, MRSA prevalence was significantly higher in Alberta and British Columbia than in the other provinces (50\%, 44\%, and $26 \%$, respectively; $\mathrm{P}<0.05)$.

Community-acquired (CA)-MRSA genotypes continue to spread in Canadian hospitals, increasing from 19.5\% of MRSA in 2007 to $31.9 \%$ in 2009 (8). Nevertheless, most cases nationwide remain attributable to health care-associated (HA)-MRSA genotypes, which are typically more resistant to conventional antibiotic therapy compared with CA-MRSA genotypes (2). CA-MRSA emergence in Canada is highly variable (7); for example, unlike some western provinces where CA-MRSA has become more prevalent than HA-MRSA, in Quebec, CA-MRSA accounts for fewer than $10 \%$ of MRSA cases.

MRSA-related infections impose a heavy financial burden on the health care system. Total direct health care costs attributable to MRSA in Canada in 2010, including MRSA-related infrastructure and management of patients infected or colonized with MRSA, were projected to be $\$ 129$ million (9). Compared with patients with uncomplicated infections, those with complicated infections are expected to account for a disproportionately large share of this expenditure because the latter generate higher per-patient hospital charges (10).

Across different infections, antibiotic therapy has been estimated to comprise only $4 \%$ of MRSA-related hospital costs in Canada, with the remainder due to hospitalization and laboratory tests (11). While cost distribution estimates have not been reported separately for complicated SSSI (cSSSI) in Canada (11), recent data show that the majority ( $81 \%$ to $97 \%$ ) of medical costs for cSSSI management in the United States are attributable to hospital ward and intensive care unit (ICU) costs, greatly exceeding antibiotic acquisition and administration costs (12). If similar expenditure distributions apply in Canada, selecting antibiotic regimens that reduce hospital length of stay and/or the intensity of resource use during hospitalization could reduce the economic burden of MRSA-related cSSSI.

In Canadian clinical practice, cSSSI too severe to be managed by local care (eg, incision of abscesses) is usually treated with antibiotics in hospital, with a follow-up course administered at home for stable patients (13). Although cSSSI may be treated by conventional agents in jurisdictions where CA-MRSA is more prevalent, intravenous (IV) vancomycin is typically used for infections when HA-MRSA is the proven or suspected pathogen. Previous analyses from other countries suggested that use of linezolid - which is available in both oral (PO) and IV formulations - can reduce hospital resource utilization compared with vancomycin, due to switching from IV to PO administration, the shorter duration of IV therapy and earlier hospital discharge $(14,15)$. However, analyses of outcomes in a multinational trial of vancomycin versus linezolid in patients with cSSTIs due to MRSA showed that the length-of-stay and early-discharge advantages for linezolid differed according to country, due to regional variation in clinical practice (16), and no study has compared the total costs of cSSSI treatment with linezolid versus vancomycin in Canada based on established clinical practice. The only previous Canadian cost simulation suggesting linezolid could be cost saving relative to vancomycin for patients with SSTIs was based on extrapolations from chart review data in the period before the availability of linezolid in Canada (17). The objective of the present study was to evaluate the potential cost impact in Quebec of using IV and PO linezolid instead of IV vancomycin to treat cases of cSSSI caused by MRSA that are severe enough to require hospitalization, based on current treatment patterns in Quebec.

\section{Analytical method}

\section{METHODS}

A net impact analysis method, which calculates resource utilization and associated costs for a particular treatment compared with an alternative was used. This pharmacoeconomic approach is one of the manufacturer requirements for drug appraisal by l'Institut national d'excellence en santé et en services sociaux (INESSS; formerly Conseil du médicament) to obtain public drug plan coverage in Quebec (18). INESSS advises the Régie de l'assurance maladie du Québec (RAMQ), which administers the provincial outpatient drug plan and the list of reimbursed medications for institutions. Net impact analyses for INESSS may include costs for treatment acquisition, preparation, administration, monitoring and management of adverse effects, although adverse effect costs were not considered in the present study. In addition, equal clinical effectiveness of linezolid and vancomycin was assumed (19).

\section{Treatment patterns and resource utilization}

Data regarding health care resource utilization for linezolid and vancomycin therapy were modelled for patients with cSSSI due to confirmed MRSA. Classical multidrug-resistant cases reflective of the high prevalence of HA-MRSA in Quebec infections severe enough to require hospitalization were focused on. Current treatment patterns in Quebec and the resulting resource utilization for this patient population were based on the expert opinion of two authors: an infectious disease specialist (ML) and a hospital pharmacist in infectious disease (DJGT). Two treatment scenarios were constructed, one based on IV linezolid followed by PO linezolid, and the other based on IV vancomycin, as depicted in Figure 1. These treatment patterns adhere to Infectious Diseases Society of America (IDSA) clinical practice guidelines for MRSA-related SSTIs (20), and are consistent with the recommendations of both products' Canadian labels $(21,22)$. In clinical practice, cSSSI inpatients considered stable enough may be discharged to complete their treatment at home (13). The base-case analysis assessed antibiotic treatment for a scenario reflective of practice in Quebec, in which patients are treated for an average of five days in hospital followed by nine days at home (based on the expert opinions of ML and DJGT). Inpatients received either IV linezolid for two days followed by PO linezolid for three days, or IV vancomycin for five days. The requirement for initial IV administration in linezolid recipients was consistent with the focus on patients with severe infections. Outpatients received either PO linezolid or IV vancomycin. Other discharge scenarios, including the full 14 days spent in hospital, were explored in sensitivity analyses. 
In addition to the two antibiotics, health care resources included materials and health care professional time for diagnostic testing, antibiotic preparation and administration, and patient monitoring. Table 1 presents specific components of health care resource utilization for MRSA-related cSSSI management with linezolid or vancomycin based on practice patterns in Quebec. Notable differences in resource utilization between linezolid and vancomycin included the lack of preparation time for IV linezolid, which is provided in a premixed IV bag, reduced preparation and administration time for $\mathrm{PO}$ linezolid administered in hospital, and the lack of preparation and administration time for outpatient treatment with PO linezolid. Linezolid also requires less monitoring of patients during outpatient treatment compared with vancomycin. It should be noted that centres in other jurisdictions may monitor antibiotic levels less frequently than what was performed in the present analysis, but this is unlikely to have a major impact on results because monitoring represents a relatively minor cost component. Data on medical supply utilization and nursing protocols for outpatient antibiotic administration and monitoring in Quebec were retrieved with the assistance of Johanne Gauthier, Clinical Nurse Consultant at Centre de santé et de services sociaux de la Montagne, Montreal.

Antibiotic use was based on per-patient antibiotic dosages recommended in the product labels $(21,22)$, as shown in Table 2. Based on expert opinion (ML and DJGT), these dosages are also reflective of the average for patients hospitalised for cSSSI in Quebec, taking into account that some patients may require lower doses (eg, for elderly patients) while others may need higher doses.

\section{Costs}

Costs associated with health care utilization patterns were estimated for the linezolid and vancomycin treatment scenarios, from the perspective of the provincial health care budget. Costs were assigned to health care resources based on unit prices and expert opinion (DJGT). Costs of health care professional time for drug preparation, administration and monitoring were based on average professional hourly rates from the Quebec Ministry of Health (23-25). The daily ward cost of hospitalization was based on 2009 data from Charles LeMoyne Hospital (Longueuil, Quebec) (26). All costs are expressed in 2010 Canadian dollars. While cost calculations were performed to the nearest cent, results are reported to the nearest dollar; therefore, calculations using intermediate values reported in the Results section may differ slightly from the reported totals or differences due to rounding.

Costs for health care resources other than antibiotics are reported in Table 1. Antibiotic acquisition costs are shown in Table 3. Diagnostic tests on admission were identical for linezolid and vancomycin, adding the same amount $(\$ 51.20)$ to inpatient treatment costs associated with both drugs (27). Outpatient drug costs included acquisition costs, wholesaler mark-up (6\%) and pharmacist fees reimbursed by RAMQ (28). These pharmacist fees included per-script charges for dispensing (\$8.44), IV medication packaging (\$5.41) and transportation $(\$ 25.00)$.

\section{Study assessments}

Results were assessed according to health care-resource category. Cost estimates are presented separately for treatment (ie, drugs), preparation, administration and monitoring, and for total costs summed across these categories.

\section{Sensitivity analyses}

To increase the generalizability of our results beyond the practice patterns for Quebec in the base-case analysis, a series of sensitivity analyses was conducted. In the first set of sensitivity analyses, overall antibiotic treatment duration was varied among seven, 10 and 14 days. The seven-day duration reflected the lower end of the range of treatment durations recommended for MRSA-related SSTI in the IDSA guidelines (20), while the 10-day duration was the lower end of the SSTI treatment period recommended in the linezolid label (21); the vancomycin label does not specify a treatment period, advising only that the total duration of therapy should be determined by the type and severity of the infection and the clinical response of the patient (22). The 14-day duration, which was also used in the base-case analysis to reflect clinical practice in Quebec, represented the upper end of the treatment period range recommended in the IDSA guidelines (20) and in the linezolid label for SSTIs (other than diabetic foot infections, for which 14 days represents the lower end of the recommended treatment period) (21). For each of these three treatment durations, varying days of inpatient and outpatient treatment were analyzed. Scenarios were modelled in which all patients spent the full treatment duration in hospital. Alternative scenarios in which all patients were treated in hospital for five days (based on expert opinion, ML and DJGT) and at home for the remainder of the treatment duration were also modelled. In addition, one 14-day treatment scenario with seven-day inpatient and seven-day outpatient treatment for linezolid recipients, versus 10-day inpatient and four-day outpatient treatment for vancomycin recipients was modelled; this scenario reflected the infection-related inpatient length of stay observed in the MRSA subgroup of a clinical trial of linezolid versus vancomycin for cSSTIs (29).

Additional sensitivity analyses were conducted for the four different treatment-duration scenarios that included outpatient treatment, in which the percentage of inpatients discharged to finish their treatment at home was varied. In this series of sensitivity analyses, $50 \%$ of vancomycin recipients were always discharged to complete treatment at home and $50 \%$ received the full treatment course in hospital. Acknowledging the significantly higher discharge rates observed for clinical trial subjects receiving linezolid compared with those receiving vancomycin $(29,30)$, the effect of varying the percentage of linezolid recipients discharged to continue treatment at home was explored. The following discharge differentials (linezolid minus vancomycin) were assessed: $0 \%, 5 \%, 10 \%$ and $25 \%$ (ie, 50\% discharged in the vancomycin arm versus $50 \%, 55 \%, 60 \%$ or $75 \%$ in the linezolid arm).

Because an average ward cost for hospitalization in Quebec was unavailable, available data from an academic hospital (Charles LeMoyne Hospital) were used. To test the sensitivity of the results to this cost, additional sensitivity analyses in which ward cost was varied by $\pm 30 \%$ of that in the base-case scenario, were performed (results not shown).

\section{Treatment costs}

\section{RESULTS}

In the base-case analysis, per-patient drug acquisition costs were $\$ 730$ higher for linezolid than for vancomycin for inpatient therapy ( $\$ 822.72$ versus $\$ 93.00$, respectively), and $\$ 114$ higher for linezolid than for vancomycin for outpatient therapy $(\$ 1,355.87$ versus $\$ 1,242.08$, respectively) (Table 4 ). The acquisition cost differential between linezolid and vancomycin was larger for inpatient treatment because of the more than sixfold lower per-unit cost of vancomycin for hospitals compared with the RAMQ outpatient drug plan ( $\$ 9.30$ versus $\$ 58.99$ per $1 \mathrm{~g}$ vial, respectively).

\section{Preparation, administration and monitoring costs}

Costs for antibiotic preparation, administration and monitoring for linezolid were all lower than for vancomycin in the base-case analysis (Figure 2). For preparation and administration, cost savings with linezolid were $\$ 87$ for inpatient treatment ( $\$ 1,550$ versus $\$ 1,637$ for vancomycin) and $\$ 1,847$ for outpatient treatment ( $\$ 0$ versus $\$ 1,847$, respectively). Corresponding cost savings for monitoring were $\$ 68$ for inpatient treatment ( $\$ 32$ versus $\$ 100$ for linezolid versus vancomycin, respectively) and $\$ 182$ for outpatient treatment ( $\$ 38$ versus $\$ 219$, respectively).

\section{Total health care costs}

In the base-case analysis, cost savings for inpatient antibiotic preparation, administration and monitoring with linezolid were insufficient to fully offset its higher drug acquisition costs compared with vancomycin. As a result, overall per-patient hospital treatment costs remained $\$ 575$ higher with linezolid compared with vancomycin ( $\$ 2,456$ versus $\$ 1,881$, respectively). 
TABLE 1

Components of health care resource utilization and associated costs in Quebec for treatment of cSSSI due to MRSA

\begin{tabular}{|c|c|c|}
\hline \multirow{2}{*}{$\begin{array}{l}\text { Health care } \\
\text { component }\end{array}$} & \multicolumn{2}{|c|}{ Health care resource } \\
\hline & Inpatient treatment & Outpatient treatment \\
\hline \multirow[t]{4}{*}{ Diagnostic tests } & - On admission (total $\$ 51.20$ ): & NA \\
\hline & - Minimum inhibitory concentration $(\times 5)$ & \\
\hline & - Hemoculture (two bottles) $(\times 1)$ & \\
\hline & - Susceptibility for Staphylococcus aureus (MRSA) (×1) & \\
\hline \multirow{28}{*}{$\begin{array}{l}\text { Antibiotic } \\
\text { preparation }\end{array}$} & - Hospital pharmacist time ( $\$ 49.02$ per $\mathrm{h})$ : & - Dispensing (\$8.44 per script/preparation delivered): \\
\hline & - Vancomycin or linezolid IV: & - Vancomycin: three preparations \\
\hline & - 10 min for the first script (patient file review, script and & - Linezolid: one script \\
\hline & validation) $(\times 1)$ & - Pharmacist time for preparation*: \\
\hline & - 20 min for subsequent scripts every three days (laboratory & 。First unit of vancomycin IV preparation at \$17.60 (×1) \\
\hline & 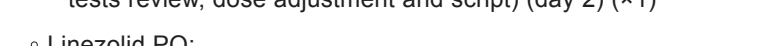 & - Subsequent units of vancomycin IV at \$14.06 (×17) \\
\hline & 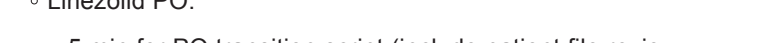 & - Medical supplies for preparation* (total \$757.71): \\
\hline & $\begin{array}{l}\text { - } 5 \text { min for PO transition script (include patient file review, } \\
\text { script and validation) }(\times 1)\end{array}$ & - Intermate (Baxter, USA) devices (×18) \\
\hline & - Assistant technician time (\$22.14 per h) & - Dextrose $5 \%$ bags $250 \mathrm{~mL}$ for vancomycin mixing $(\times 18)$ \\
\hline & - Vancomycin: & $\begin{array}{l}\text { - Sterile water } 10 \mathrm{~mL} / \mathrm{g} \text { for vancomycin hydrochloride dilution } \\
(\times 18)\end{array}$ \\
\hline & $\begin{array}{l}\text { - } 10 \mathrm{~min} / \mathrm{script} \text { for vancomycin dilution and IV bag preparation } \\
(\times 10)\end{array}$ & . 60 mL luer-lock syringes (hospital cost) $(\times 18)$ \\
\hline & - Linezolid: & $\begin{array}{l}- \text { Mini-spikes (one mini-spike/six doses prepared) (hospital cost) } \\
\quad(\times 3)\end{array}$ \\
\hline & pills $(\times 10)$ & $\begin{array}{l}\text { - Dispensing pins with 'safesite' valve (one dispensing pin/six } \\
\text { doses prepared) (hospital cost) }(\times 3)\end{array}$ \\
\hline & - ivieuicar suppiles. & - 18 gauge $\times 1.5 \mathrm{~cm}$ needles (one needle/six doses prepared) \\
\hline & - Vancomycin (total \$42.79): & $(\times 3)$ \\
\hline & - Primary IV line for $\mathrm{NaCl}$ bag $(\times 1)$ & - Packaging* (\$5.41 per package): \\
\hline & $\begin{array}{l}\text { - } \mathrm{NaCl} 0.9 \% \text { bag } 250 \mathrm{~mL}(20 \mathrm{~mL} / \mathrm{h} \text { to keep the vein open; } \\
\text { total of } 480 \mathrm{~mL} / \text { day })(\times 10)\end{array}$ & - Vancomycin: three packages \\
\hline & - IV bag-mix identification stickers $(\times 10)$ & - Transportation* (\$25 per package): \\
\hline & - Dextrose $5 \%$ bags $250 \mathrm{~mL}$ for vancomycin mixing $(\times 10)$ & - Vancomycin: three packages \\
\hline & $\begin{array}{l}\text { - Sterile water } 10 \mathrm{~mL} / \mathrm{g} \text { for vancomycin hydrochloride dilution } \\
(\times 10)\end{array}$ & \\
\hline & - 60 mL luer-lock syringes $(\times 10)$ & \\
\hline & - Mini-spikes (one mini-spike/20 doses prepared) $(\times 1)$ & \\
\hline & $\begin{array}{l}\text { - Dispensing pins with 'safesite' valve (one dispensing } \\
\text { pin/20 doses prepared) }(\times 1)\end{array}$ & \\
\hline & - 18 gauge $\times 1.5 \mathrm{~cm}$ needles (one needle/five doses prepared) $(\times 2)$ & \\
\hline & ○ Linezolid (total \$15.31): & \\
\hline & - Primary IV line for $\mathrm{NaCl}$ bag $(\times 1)$ & \\
\hline & $\begin{array}{l}\text { - } \mathrm{NaCl} 0.9 \% \text { bag } 250 \mathrm{~mL}(20 \mathrm{~mL} / \mathrm{h} \text { to keep the vein open; total } \\
\text { of } 480 \mathrm{~mL} / \text { day })(\times 4)\end{array}$ & \\
\hline & - IV bag-mix identification stickers $(\times 4)$ & \\
\hline \multirow[t]{9}{*}{$\begin{array}{l}\text { Antibiotic } \\
\text { administration }\end{array}$} & $\begin{array}{l}\text { - Nurse time }(\$ 30.75 \text { per } \mathrm{h}) \text { : } \\
\text { - Vancomycin or linezolid IV: }\end{array}$ & $\begin{array}{l}\text { - Nurse time for administration* (twice a day for nine days at } \$ 30.75 \\
\text { per hour): }\end{array}$ \\
\hline & $\begin{array}{l}\text { - First IV bag: } 30 \text { min/infusion for IV line setup, injection access, } \\
\text { bag installation and bag removal at end of treatment }(\times 1)\end{array}$ & $\begin{array}{l}\text { - } 30 \text { min/infusion for PICC line connection to Intermate to start } \\
\text { vancomycin IV infusion }(\times 18)\end{array}$ \\
\hline & - 10 min/infusion every $12 \mathrm{~h}$ to install and change IV bag & - 25 min/infusion for disconnection and IV line bandage $(\times 18)$ \\
\hline & (vancomycin ×9; linezolid: ×3) & $\circ 30 \mathrm{~min} /$ infusion for nurse transportation $(\times 18)$ \\
\hline & - Linezolid PO during 3 days: & - Medical supplies for administration* (total \$48.24): \\
\hline & - 3 min every $12 \mathrm{~h}$ to review dose and deliver linezolid & . $10 \mathrm{~mL}$ syringes $(\times 36)$ \\
\hline & tablet to patient $(\times 6)$ & $\circ 20$ gauge or 22 gauge $\times 2.5 \mathrm{~cm}$ needles $(\times 36)$ \\
\hline & - Ward hospitalization (\$291.02 per day) & - Heparin $100 \mathrm{U} / \mathrm{mL}$ vials $(\times 18)$ \\
\hline & & - $\mathrm{NaCl} 0.9 \%$ single-use vials $(\times 18)$ \\
\hline
\end{tabular}


TABLE 1 - CONTINUED

Components of health care resource utilization and associated costs in Quebec for treatment of cSSSI due to MRSA

\begin{tabular}{|c|c|c|}
\hline \multirow{2}{*}{$\begin{array}{l}\text { Health care } \\
\text { component }\end{array}$} & \multicolumn{2}{|c|}{ Health care resource } \\
\hline & Inpatient treatment & Outpatient treatment \\
\hline \multirow[t]{18}{*}{ Monitoring } & - Hospital pharmacist time ( $\$ 49.20$ per $\mathrm{h})$ : & - Physician visits for evaluation (\$37.70 per visit): \\
\hline & - Evaluation of vancomycin pharmacokinetics: & - Vancomycin: patient visit for evaluation every three days $(\times 3)$ \\
\hline & - 60 min for the first evaluation (day 3$)(\times 1)$ & - Linezolid: patient visit for evaluation at the end of treatment $(\times 1)$ \\
\hline & - $15 \mathrm{~min}$ for subsequent evaluation every three days (day 5) $(\times 1)$ & - CLSC nurse time for monitoring* $(\$ 30.75$ per $h)$ : \\
\hline & • Phlebotomist time (\$30.75 per h): & - 8 min to draw blood for blood tests at baseline and every three \\
\hline & - Draw blood for blood tests: $8 \mathrm{~min}$ at baseline and every three & days $(\times 3)$ \\
\hline & days (day 1,4$)(\times 2)$ & - $10 \mathrm{~min} /$ day (5 min twice a day) for vital signs monitoring $(\times 9)$ \\
\hline & - Nurse time $(\$ 30.75$ per $h)$ : & $\circ 45 \mathrm{~min}$ to change bandage once a week $(\times 2)$ \\
\hline & $\circ 5$ min per day to measure vital signs $(\times 5)$ & - Medical supplies for monitoring* (total \$1.70): \\
\hline & - Laboratory blood testing (vancomycin total $\$ 16$; linezolid total $\$ 10$ ): & - Venous blood collection tubes for hematological and biochemistry \\
\hline & - Blood tests and platelets at baseline and every three days (day 1 , & tests $(\times 9)$ \\
\hline & 4) (vancomycin ×5; linezolid ×2) & • 10 mL-12 mL hypodermic syringes (×3) \\
\hline & $\begin{array}{l}\circ \text { Creatinine at baseline and every three days (day } 1,4) \\
(\text { vancomycin } \times 5 \text {; linezolid } \times 2)\end{array}$ & \\
\hline & $\begin{array}{l}\text { - Electrolytes (potassium, sodium, bicarbonate, chloride, BUN and } \\
\text { glucose) at baseline only }(\times 1)\end{array}$ & \\
\hline & - C-reactive protein at baseline only $(\times 1)$ & \\
\hline & - Medical supplies for blood testing (total \$1.14): & \\
\hline & $\begin{array}{l}\text { - Venous blood collection tubes for hematological and biochemistry } \\
\text { tests }(\times 6)\end{array}$ & \\
\hline & - $10 \mathrm{~mL}-12 \mathrm{~mL}$ hypodermic syringes $(\times 2)$ & \\
\hline
\end{tabular}

*Applicable to intravenous (IV) antibiotics only. BUN Blood urea nitrogen; CLSC Centre local de services communautaires (community service centre); cSSSI Complicated skin and skin-structure infection; IV Intravenous; MRSA Methicillin-resistant Staphylococcus aureus; NA Not applicable; NaCI Sodium chloride; PICC Peripherally inserted central catheter; PO Per oral

\section{TABLE 2}

Recommended per-patient antibiotic dosages used in Canada to treat cSSSI caused by MRSA $(21,22)$

\begin{tabular}{lccc}
\hline Antibiotic & Route & Dose, $\mathbf{m g}$ & Frequency \\
\hline Linezolid & IV & 600 & q12h \\
& PO & 600 & BID \\
Vancomycin & IV & 1000 & q12h \\
\hline
\end{tabular}

BID Twice daily; cSSSI Complicated skin and skin-structure infection; IV Intravenous; MRSA Methicillin-resistant Staphylococcus aureus; PO Per oral; q12h Every $12 \mathrm{~h}$

In contrast, for outpatient therapy, the large savings from antibiotic preparation, administration and monitoring with linezolid compared with vancomycin exceeded the acquisition cost differential. Per-patient outpatient treatment costs were $\$ 1,915$ lower with linezolid than with vancomycin ( $\$ 1,394$ versus $\$ 3,308$, respectively).

The cost saving with linezolid for outpatient therapy was greater than its higher cost for inpatient therapy in the base-case analysis. Consequently, for both courses of treatment combined (five days in hospital followed by nine days at home), linezolid reduced total perpatient treatment costs compared with vancomycin, with overall cost savings of $\$ 1,339$ ( $\$ 3,850$ versus $\$ 5,189$, respectively).

Sensitivity analyses

The sensitivity analyses in which treatment duration and ratio of inpatient to outpatient treatment were varied demonstrated that the cost differential between linezolid and vancomycin was sensitive to the number of days of treatment spent in hospital versus at home (Figure 3). Scenarios with a high proportion of treatment days spent at home favoured linezolid, whereas scenarios with a high number of treatment days spent in hospital favoured vancomycin. Notably, linezolid saved $\$ 712$ relative to vancomycin $(\$ 4,443$ versus $\$ 5,155$, respectively) in the 14-day treatment scenario with seven and 10 days
TABLE 3

Acquisition costs to hospitals and the public drug plan in Quebec for linezolid and vancomycin

\begin{tabular}{lccc}
\hline & \multicolumn{2}{c}{ Unit cost, \$ } \\
\cline { 3 - 4 } Antibiotic & $\begin{array}{c}\text { Dosage form/ } \\
\text { strength }\end{array}$ & $\begin{array}{c}\text { Hospital } \\
\text { (inpatient treatment) }\end{array}$ & $\begin{array}{c}\text { RAMQ (28) } \\
\text { (outpatient } \\
\text { treatment) }\end{array}$ \\
\hline Linezolid & $\begin{array}{c}300 \mathrm{~mL} \text { infusion } \\
\text { bag (2 mg/mL) }\end{array}$ & 97.47 & - \\
& $600 \mathrm{mg}$ oral tablet & 72.10 & $70.64^{*}$ \\
Vancomycin $1 \mathrm{~g}$ vial & 9.30 & $58.99^{*}$
\end{tabular}

*Plus 6\% wholesaler markup. RAMQ Régie de l'assurance maladie du Québec

TABLE 4

Per-patient treatment costs (including diagnostic tests) in Quebec for inpatient and outpatient therapy for cSSSI caused by methicillin-resistant Staphylococcus aureus

\begin{tabular}{lccc}
\hline & & \multicolumn{2}{c}{ Treatment cost, \$ } \\
\cline { 3 - 4 } Antibiotic & Dosage form & Inpatient & Outpatient \\
\hline Linezolid & IV & 390.00 & - \\
& PO & 432.72 & $1,355.87$ \\
Vancomycin & IV and PO & 822.72 & $1,355.87$ \\
\hline
\end{tabular}
cSSSI Complicated skin and skin-structure infection; IV Intravenous; PO Per oral

of inpatient treatment for linezolid and vancomycin, respectively this scenario was based on clinical trial data (29).

In the sensitivity analyses in which $50 \%$ of vancomycin recipients were discharged to continue therapy at home, increasing the percentage of linezolid recipients discharged to home from $50 \%$ to $75 \%$ 


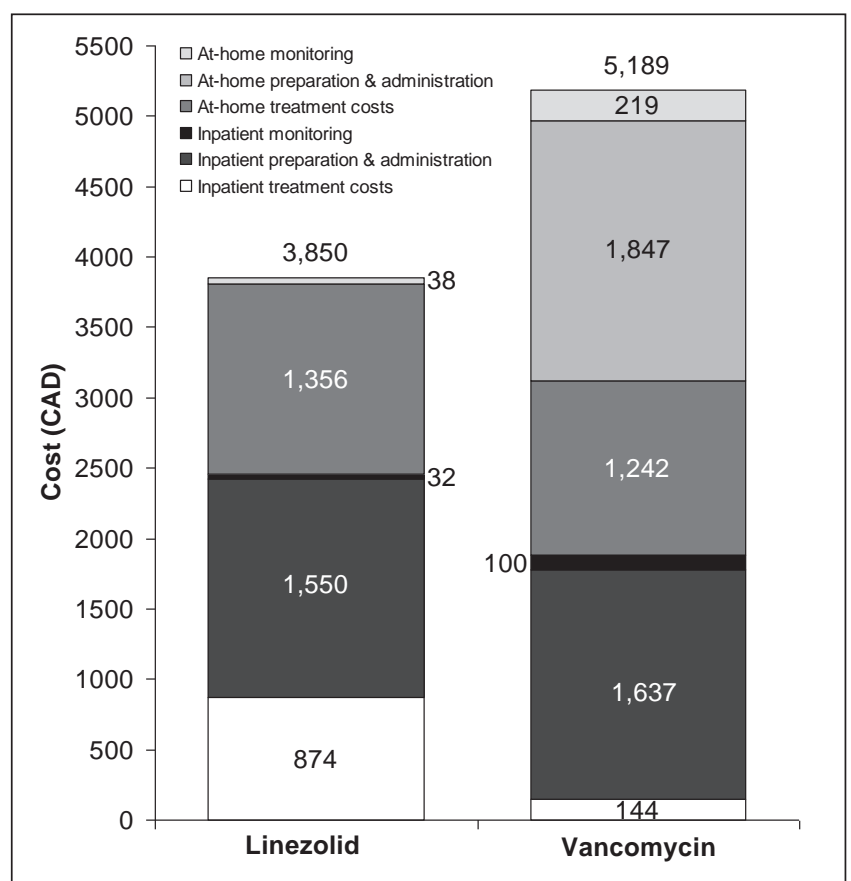

Figure 2) Per-patient health care costs associated with linezolid and vancomycin therapy in Quebec for complicated skin and skin-structure infection caused by methicillin-resistant Staphylococcus aureus. CAD Canadian dollars

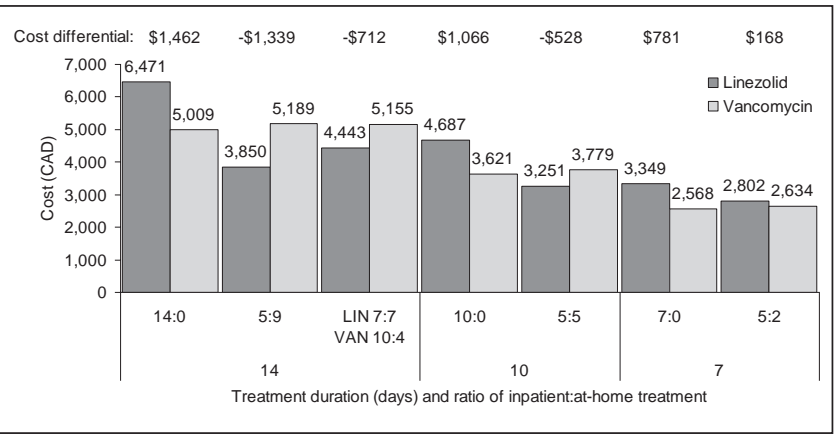

Figure 3) Results of sensitivity analyses with varying treatment duration and number of days of inpatient versus outpatient treatment for complicated skin and skin-structure infection. Positive cost differentials indicate perpatient cost savings for vancomycin (VAN); negative cost differentials indicate per-patient cost savings for linezolid (LIN). CAD 2010 Canadian dollars

increasingly favoured linezolid (Figure 4). However, regardless of treatment duration or the proportion of treatment days spent in hospital versus at home, results were not as favourable for linezolid as in the first series of sensitivity analyses in which $100 \%$ of patients in both arms were discharged to complete treatment at home.

Varying hospital ward cost by $\pm 30 \%$ of the base-case value had little impact on the observed trends (data not shown).

\section{DISCUSSION}

The present net impact analysis suggests that despite its higher acquisition cost compared with vancomycin, linezolid is potentially cost saving for the treatment of MRSA-related cSSSI in current clinical practice in Quebec. Projected cost savings with linezolid are primarily attributable to reduced costs for outpatient antibiotic preparation, administration and monitoring. In addition, the acquisition cost for vancomycin in the community setting is much higher than for hospitals ( $\$ 58.99$ versus $\$ 9.30$ per $1 \mathrm{~g}$ vial, respectively), further improving the cost savings made possible by the availability of PO linezolid for discharged patients.

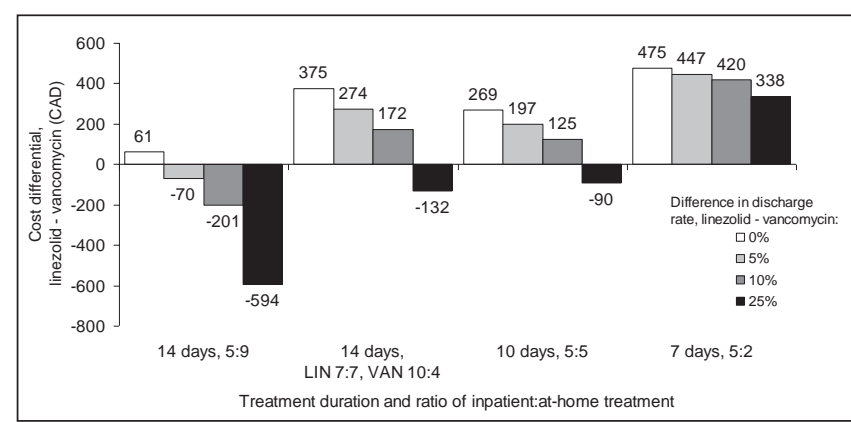

Figure 4) Results of sensitivity analyses with varying percentage of inpatients discharged to home, treatment duration, and number of days of inpatient versus outpatient treatment for complicated skin and skin-structure infection. Positive cost differentials indicate per-patient cost savings for vancomycin (VAN); negative cost differentials indicate per-patient cost savings for linezolid (LIN). CAD 2010 Canadian dollars

The reduced overhead associated with linezolid PO administration during inpatient treatment also partially offsets the higher acquisition cost of linezolid. Beyond its cost implications, this finding suggests that use of linezolid would be expected to allow for improved discharge dynamics, and possibly better efficiency in allocating professional resources, in terms of time and duties. The previously unmet need for an oral agent to allow more efficient health care delivery was identified in an analysis of treatment patterns for MRSA-related SSTI in Canadian hospitals in the period before the availability of linezolid, which revealed that $83 \%$ of patients who were eligible to be switched from IV to PO therapy did not switch, primarily because the attending physicians considered no effective oral therapy was then available (13).

Note that our analyses focused on patients with severe infections associated with HA-MRSA, for whom vancomycin and linezolid are the main antibiotic options. In other jurisdictions where CA-MRSA predominates, co-trimoxazole or clindamycin may be alternatives for some patients with cSSSI. Overall treatment costs for cSSSI would clearly be reduced if these traditional agents could be used; however, these agents are not a viable alternative for the patients targeted in our analyses.

Our sensitivity analyses revealed that the relative number of treatment days spent in hospital and at home had a major influence on the cost differential between linezolid and vancomycin. Sensitivity of cost results to this ratio of inpatient length of stay to outpatient treatment duration was qualitatively consistent with results of a decision-analytic model comparing different strategies of therapy in the United States (US) with linezolid and vancomycin for MRSA-related cSSTIs (31).

The second series of sensitivity analyses demonstrated that cost results were also sensitive to the differential in discharge rates between linezolid and vancomycin. Greater potential savings were demonstrated in scenarios with higher percentages of patients discharged to home with linezolid, which is likely to be realistic in clinical practice due to the greater ease of use allowed by the availability of the oral formulation. Assumptions of decreased inpatient stays and duration of IV antibiotic treatment for linezolid compared with vancomycin are also supported by data from clinical trials in which investigators could switch from IV linezolid to PO linezolid at their discretion. For example, in Study 128, a randomized, open-label, multinational trial of IV or PO linezolid versus IV vancomycin involving 1200 adult patients hospitalized with cSSTIs due to suspected or proven MRSA (32), linezolid treatment was associated with significantly shorter length of stay, decreased IV antibiotic treatment duration and higher discharge rates (29). A more recent randomized, open-label, multicentre trial of IV or PO linezolid versus IV vancomycin involving 1052 adult patients hospitalized with cSSTIs proven to be due to MRSA also found that linezolid treatment was associated with significantly shorter length of stay and decreased IV antibiotic treatment 
duration (33). These large studies confirmed findings from an earlier randomized, open-label, multinational trial of linezolid versus vancomycin in patients hospitalized with infections due to suspected or proven MRSA; in the subgroup of 230 subjects with cSSTIs, patients who received linezolid (initiated IV, and either continued or switched to $\mathrm{PO}$ at investigator discretion) had significantly shorter length of stay, fewer days of IV therapy and more early discharges than those who received IV vancomycin (30).

Our cost results supported predictions from a previous Canadian simulation study, from the period before availability of linezolid, that linezolid could be cost saving relative to vancomycin for patients with MRSA-related SSTI (17). The base-case simulation estimated that the total cost of treatment to the Ontario health care system would be approximately $\$ 750$ lower for patients receiving linezolid instead of vancomycin. Similar to our study, cost savings with linezolid in sensitivity analyses were dependent on patients receiving linezolid being eligible for early discharge.

These Canadian results are qualitatively similar to those from previous cost analyses of linezolid versus vancomycin in the US, in which savings were attributable mainly to reduced length of stay and duration of IV treatment with linezolid $(34,35)$. Savings with linezolid of the same order of magnitude as in Canada and the US have also been projected for Europe. Two models using the identical decision-analytic approach, based on clinical data from Study 128 (32), assessed the costs of empirical therapy for cSSTI in France and Germany $(36,37)$. Both models found that the additional acquisition cost for linezolid was offset by expected reductions in hospitalization costs due to shorter IV treatment duration and earlier discharge compared with vancomycin. Similar to our sensitivity analyses, those for the French and German models revealed that the cost differential between linezolid and vancomycin was sensitive to days of hospitalization and the duration of treatment.

Large potential savings were also suggested by a single-centre, randomized trial in the US of 60 adult patients with proven MRSA-related lower limb cSSTIs (38). In this study, although daily medication charges were higher for PO linezolid than for IV vancomycin, linezolid was associated with a shorter median length of stay, reduced total hospital charges per patient and lower daily cost of subsequent outpatient therapy.

Although the results and studies discussed to date have all investigated patients initiating IV antibiotic treatment in hospital, initial outpatient treatment among patients with SSTIs who do not require hospitalization was also shown to be less costly with $\mathrm{PO}$ linezolid than with IV antibiotics in a small $(\mathrm{n}=20)$ US study on outpatient parenteral antimicrobial therapy (OPAT) (39). However, despite the availability of oral linezolid in Quebec, it has not been adopted as an alternative to OPAT because the current provincial formulary reimburses outpatient linezolid only in cases of lack of response or intolerance to vancomycin.

Our study is subject to a number of limitations. These analyses are based on expert opinion of current practice patterns, duration of inpatient and outpatient treatment, and resource utilization in Quebec, rather than objective measurements of these parameters. The modelled scenarios are based largely on the experience of the clinician authors (ML and DJGT) and their awareness of clinical practice at other centres in Quebec. While we believe these scenarios accurately reflect the typical situation for patients requiring hospitalization for severe cSSSI, we are unable to rule out potential bias in our assumptions in the absence of a comprehensive audit of treatment patterns across the province, which was beyond the scope of the present study.

We did not consider adverse events due to antibiotic therapy. Although similar numbers of drug-related adverse events were reported in the linezolid and vancomycin arms of large clinical trials $(32,33)$, the cost of managing adverse events could influence the differential in overall health care costs between these agents if the distribution of adverse events in clinical practice differs between agents, and if management costs differ among adverse events. For example, outpatient IV lines may be associated with complications, such as phlebitis (40), but these were not modelled. Previous cost-effectiveness analyses have incorporated lower rates of discontinuation due to intolerable adverse events for linezolid compared with vancomycin $(36,37)$.

We also did not model the potential cost implications of using vancomycin in hospital but switching to linezolid for outpatient care. This could be a reasonable strategy from an economic point of view, although in practice physicians prefer not to switch away from a successful treatment regimen.

Furthermore, the generalizability of our findings is limited by the fact that we did not investigate how uniform drug acquisition costs, costs of other health care resources or treatment patterns may be across Canada. While we do not expect unit costs to differ sufficiently among provinces to change our conclusions qualitatively, it is possible that different practice patterns yield large differences in total costs compared with our results. For example, in jurisdictions with less labour-intensive administration and monitoring of at-home IV antibiotics, outpatient costs may be lower than in our scenarios based on nurse protocols in Quebec. However, some key assumptions were conservative, notably the need for inpatient IV linezolid, which might be expected to bias the analyses against linezolid. Therefore, we believe our finding of cost savings with linezolid regimens to be broadly relevant across Canada, consistent with the previously mentioned studies from Europe and the US.

Our analyses also do not include previously reported differences in efficacy and outcomes for linezolid compared with vancomycin. Although a meta-analysis of clinical trials for the two drugs did not detect a statistically significant difference in outcomes (19), other studies have suggested that, compared with vancomycin, linezolid yields a higher rate of clinical success in cSSTI $(33,41)$, lower rehospitalization rates (42) and higher rates of bacterial eradication (19). Inclusion of such differences would be expected to influence results through their impact on treatment duration and/or intensity.

\section{CONCLUSIONS}

Assuming equal treatment efficacy, the present net impact analysis predicts a reduction in overall health care resource utilization and costs associated with use of IV and PO linezolid instead of IV vancomycin to treat MRSA-related cSSSI. More often than not, reduction in drug costs tends to drive changes in practice, but it is important that the costs to the entire health care system be considered in decision making. Results of the present study are consistent with a large body of evidence demonstrating that the use of vancomycin requires substantial additional professional time and health care resource utilization compared with linezolid, both in hospital and after discharge. Thus, linezolid may be a treatment strategy for reducing the burgeoning health care and economic burden of MRSA-related cSSSI in Quebec.

ACKNOWLEDGEMENTS: Martine Pettigrew and Daniel Thirion made substantial contributions to study conception and design, and acquisition of data. Michael Libman made substantial contributions to study conception and design. Giovanni Zanotti made substantial contributions to study conception. All authors made substantial contributions to analysis and interpretation of data, and participated in drafting the manuscript or revising it critically for important intellectual content. All authors jointly shared final approval of the version of the article to be published. Martine Pettigrew had full access to all of the data in the study and takes responsibility for the integrity of the data and the accuracy of the data analysis. The authors thank Johanne Gauthier, BScInf, Clinical Nurse Consultant at Centre de santé et de services sociaux de la Montagne, Montreal, Quebec, for providing data on medical supply utilization and nursing protocols for outpatient antibiotic administration and monitoring in Quebec. The authors are also grateful to the Editor-in-Chief and Associate Editors of the Canadian Journal of Infectious Disease and Medical Microbiology and two anonymous reviewers for constructive comments that improved the manuscript. W Mark Roberts PhD, Montreal, Quebec, provided writing assistance in the development of the manuscript. 
DISCLOSURE: Martine Pettigrew is a consultant for Pfizer Canada Inc, manufacturer of linezolid. Michael Libman and Daniel Thirion received compensation from Pfizer Canada Inc for time spent working on this analysis. Giovanni Zanotti is an employee of Pfizer Canada Inc. Pfizer Canada Inc provided financial support for the analysis described in this article, for writing assistance and for publishing this article.

\section{REFERENCES}

1. Canadian Nosocomial Infection Surveillance Program. Surveillance for methicillin-resistant Staphylococcus aureus (MRSA) in patients hospitalized in Canadian acute-care hospitals participating in CNISP: 2006-2007 preliminary results. <www.phac-aspc.gc.ca/noissinp/reports-rapport/mrsa-sarm_result-eng.php> (Accessed October 11, 2011).

2. Naimi TS, LeDell KH, Como-Sabetti K, et al. Comparison of community-and health care-associated methicillin-resistant Staphylococcus aureus infection. JAMA 2003;290:2976-84.

3. May AK. Skin and soft tissue infections. Surg Clin North Am 2009;89:403-20.

4. Adam HJ, Allen VG, Currie A, et al. Community-associated methicillin-resistant Staphylococcus aureus: Prevalence in skin and soft tissue infections at emergency departments in the Greater Toronto Area and associated risk factors. CJEM 2009;11:439-46.

5. Achiam CC, Fernandes CM, McLeod SL, et al. Methicillinresistant Staphylococcus aureus in skin and soft tissue infections presenting to the emergency department of a Canadian academic health care center. Eur J Emerg Med 2011;18:2-8.

6. Stenstrom R, Grafstein E, Romney M, et al. Prevalence of and risk factors for methicillin-resistant Staphylococcus aureus skin and soft tissue infection in a Canadian emergency department. CJEM 2009;11:430-8.

7. Borgundvaag B, Ng W, Willey B, et al. Prevalence of CA-MRSA in purulent skin and soft tissue infections in patients presenting to Canadian emergency departments. [Abstract presented at the Canadian Association of Emergency Physicians Annual Conference, St John's, June 5 to 9, 2011]. CJEM 2011;13:185-6.

8. Nichol KA, Adam HJ, Hussain Z, et al. Comparison of communityassociated and health care-associated methicillin-resistant Staphylococcus aureus in Canada: Results of the CANWARD 2007. 2009 study. Diagn Microbiol Infect Dis 2011;69:320-5.

9. Goetghebeur M, Landry PA, Han D, Vicente C. Methicillin-resistant Staphylococcus aureus: A public health issue with economic consequences. Can J Infect Dis Med Microbiol 2007;18:27-34.

10. Lipsky BA, Weigelt JA, Gupta V, Killian A, Peng MM. Skin, soft tissue, bone, and joint infections in hospitalized patients: Epidemiology and microbiological, clinical, and economic outcomes. Infect Control Hosp Epidemiol 2007;28:1290-8.

11. Kim T, Oh PI, Simor AE. The economic impact of methicillinresistant Staphylococcus aureus in Canadian hospitals. Infect Control Hosp Epidemiol 2001;22:99-104.

12. Wright BM, Eiland EH III. Retrospective analysis of clinical and cost outcomes associated with methicillin-resistant Staphylococcus aureus complicated skin and skin structure infections treated with daptomycin, vancomycin, or linezolid. J Pathogens 2011;2011:347969.

13. Conly JM, Stiver HG, Weiss KA, Becker DL, Rosner AJ, Miller E. A retrospective analysis of practice patterns in the treatment of methicillin-resistant Staphylococcus aureus skin and soft tissue infections at three Canadian tertiary care centres. Can J Infect Dis 2003;14:315-21.

14. Grau S, Rubio-Terres C. Pharmacoeconomics of linezolid. Expert Opin Pharmacother 2008;9:987-1000.

15. Nathwani D. Impact of methicillin-resistant Staphylococcus aureus infections on key health economic outcomes: Does reducing the length of hospital stay matter? J Antimicrob Chemother 2003;51(Suppl 2):ii37-ii44.

16. Itani KMF, Sorensen S, Stokes M, Shelbaya A, McKinnon P. A regional comparison of resource utilization in patients with methicillin-resistant Staphylococcus aureus (MRSA) complicated skin and soft tissue infections (CSSTI) treated with linezolid vs vancomycin. [Presentation O-1791]. 49th Interscience Conference on Antimicrobial Agents and Chemotherapy (ICAAC), San Francisco, September 12 to 15, 2009.
17. Rosner AJ, Becker DL, Wong AH, Miller E, Conly JM. The costs and consequences of methicillin-resistant Staphylococcus aureus infection treatments in Canada. Can J Infect Dis Med Microbiol 2004;15:213-20.

18. Selecting medication for coverage in Quebec: A responsible, transparent process. Information on the scientific evaluation process of medication. Quebec City, QC: Conseil du médicament, February, 2007.

19. Dodds TJ, Hawke CI. Linezolid versus vancomycin for MRSA skin and soft tissue infections (systematic review and meta-analysis). ANZ J Surg 2009;79:629-35.

20. Liu C, Bayer A, Cosgrove SE, et al. Clinical practice guidelines by the Infectious Diseases Society of America for the treatment of methicillin-resistant Staphylococcus aureus infections in adults and children. Clin Infect Dis 2011;52:e18-e55.

21. PrZyvoxam (linezolid) product monograph. Kirkland, Quebec: Pfizer Canada Inc, October 5, 2009.

22. PrVancomycin hydrochloride for injection, USP, Product Monograph. Richmond Hill, Ontario: Pharmaceutical Partners of Canada Inc, March 7, 2011.

23. Régie de l'assurance maladie du Québec. Manuel des pharmaciens, Update No. 32. <www.ramq.gouv.qc.ca/fr/professionnels/ manuels/260/000_complet_pharm.pdf> (Accessed October 11, 2011).

24. Ministère de la santé et des services sociaux du Québec. Entente intervenue entre le ministre de la Santé et des Services sociaux et l'Association des pharmaciens des établissements de santé du Québec relative aux conditions de travail des pharmaciens exerçant en établissement de santé et de services sociaux: 2006-2010. <http:// msssa4.msss.gouv.qc.ca/fr/document/d26ngest.nsf/3f4763bf7e3c23a7852 5660f00727c27/f74712b4305c5e298525715d0048760e/\$FILE/ Entente\%20APES\%20(2006-2010).pdf> (Accessed October 11, 2011).

25. Ministère de la santé et des services sociaux du Québec. Nomenclature des titres d'emploi, des libellés, des taux et des échelles de salaire du réseau de la santé et des services sociaux à partir du 1er avril 2010 . <www.cpnsss.gouv.qc.ca/download.php?f=f 4f879aaaaed42ae7d59ef8ff90859b2 > (Accessed October 11, 2011).

26. Rapport Financier Annuel. Longeuil, QC: Charles LeMoyne Hospital, March 31, 2009.

27. Ministère de la santé et des services sociaux du Québec. Répertoire Québécois et système de mesure des procédures de biologie médicale. $<$ http://publications.msss.gouv.qc.ca/acrobat/f/ documentation/2011/11-922-01W.pdf> (Accessed October 11, 2011).

28. Régie de l'assurance maladie du Québec. Liste des médicaments. $<$ www.ramq.gouv.qc.ca/fr/regie/publications-legales/pages/listemedicaments.aspx $>$ (Accessed October 11, 2011).

29. Itani KM, Weigelt J, Li JZ, Duttagupta S. Linezolid reduces length of stay and duration of intravenous treatment compared with vancomycin for complicated skin and soft tissue infections due to suspected or proven methicillin-resistant Staphylococcus aureus (MRSA). Int J Antimicrob Agents 2005;26:442-8.

30. Li Z, Willke RJ, Pinto LA, et al. Comparison of length of hospital stay for patients with known or suspected methicillin-resistant Staphylococcus species infections treated with linezolid or vancomycin: A randomized, multicenter trial. Pharmacotherapy 2001;21:263-74.

31. Bounthavong M, Hsu DI, Okamoto MP. Cost-effectiveness analysis of linezolid versus vancomycin in treating methicillin-resistant Staphylococcus aureus complicated skin and soft tissue infections using a decision analytic model. Int J Clin Pract 2009;63:376-86.

32. Weigelt J, Itani K, Stevens D, Lau W, Dryden M, Knirsch C. Linezolid versus vancomycin in treatment of complicated skin and soft tissue infections. Antimicrob Agents Chemother 2005;49:2260-6.

33. Itani KM, Dryden MS, Bhattacharyya H, Kunkel MJ, Baruch AM, Weigelt JA. Efficacy and safety of linezolid versus vancomycin for the treatment of complicated skin and soft-tissue infections proven to be caused by methicillin-resistant Staphylococcus aureus. Am J Surg 2010;199:804-16.

34. McKinnon PS, Sorensen SV, Liu LZ, Itani KM. Impact of linezolid on economic outcomes and determinants of cost in a clinical trial evaluating patients with MRSA complicated skin and soft-tissue infections. Ann Pharmacother 2006;40:1017-23.

35. McCollum M, Sorensen SV, Liu LZ. A comparison of costs and hospital length of stay associated with intravenous/oral linezolid or intravenous vancomycin treatment of complicated skin and 
soft-tissue infections caused by suspected or confirmed methicillinresistant Staphylococcus aureus in elderly US patients.

Clin Ther 2007;29:469-77.

36. De Cock E, Sorensen S, Levrat F, et al. Cost-effectiveness of linezolid versus vancomycin for hospitalized patients with complicated skin and soft-tissue infections in France. Med Mal Infect 2009;39:330-40.

37. Schürmann D, Sorensen SV, De Cock E, Duttagupta S, Resch A. Cost-effectiveness of linezolid versus vancomycin for hospitalised patients with complicated skin and soft-tissue infections in Germany. Eur J Health Econ 2009;10:65-79.

38. Sharpe JN, Shively EH, Polk HC, Jr. Clinical and economic outcomes of oral linezolid versus intravenous vancomycin in the treatment of MRSA-complicated, lower-extremity skin and softtissue infections caused by methicillin-resistant Staphylococcus aureus. Am J Surg 2005;189:425-8.
39. Stein GE, Schooley SL, Havlichek DH, Nix DE. Outpatient intravenous antibiotic therapy compared with oral linezolid in patients with skin and soft tissue infections: A pharmacoeconomic analysis. Infect Dis Clin Pract 2008;16:235-9.

40. Malach T, Jerassy Z, Rudensky B, et al. Prospective surveillance of phlebitis associated with peripheral intravenous catheters. Am J Infect Control 2006;34:308-12.

41. Logman JF, Stephens J, Heeg B, et al. Comparative effectiveness of antibiotics for the treatment of MRSA complicated skin and soft tissue infections. Curr Med Res Opin 2010;26:1565-78.

42. Mullins CD, Hsu VD, Cooke CE, Shelbaya A, Wallace AE, Perencevich EN. Rehospitalization rates among linezolid versus vancomycin users. Am J Pharm Benefits 2011;3:e1-e13. 


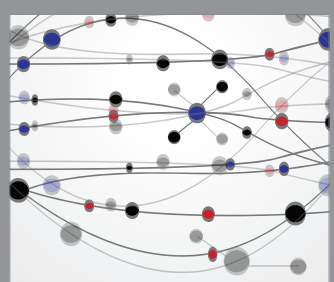

The Scientific World Journal
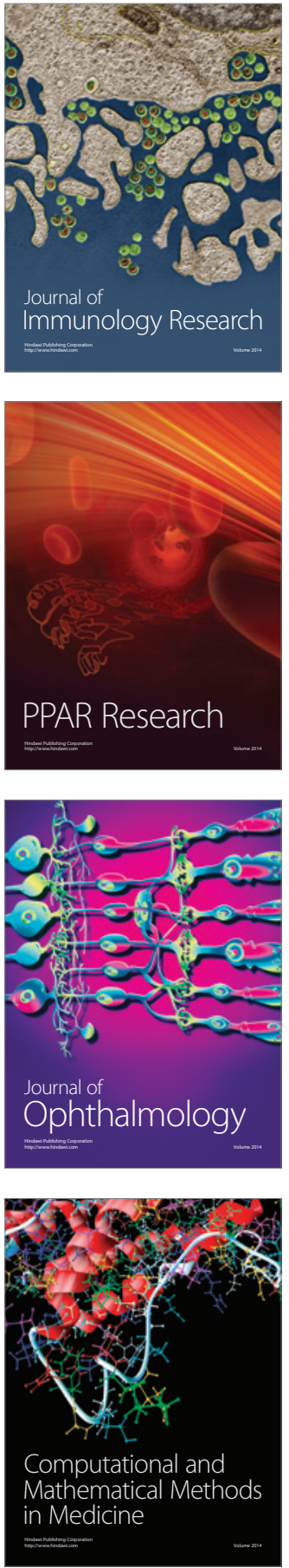

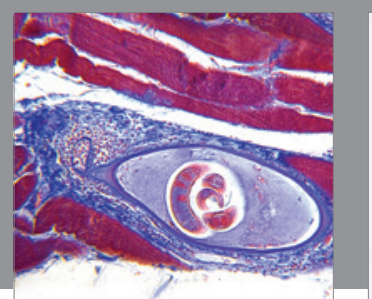

Gastroenterology Research and Practice

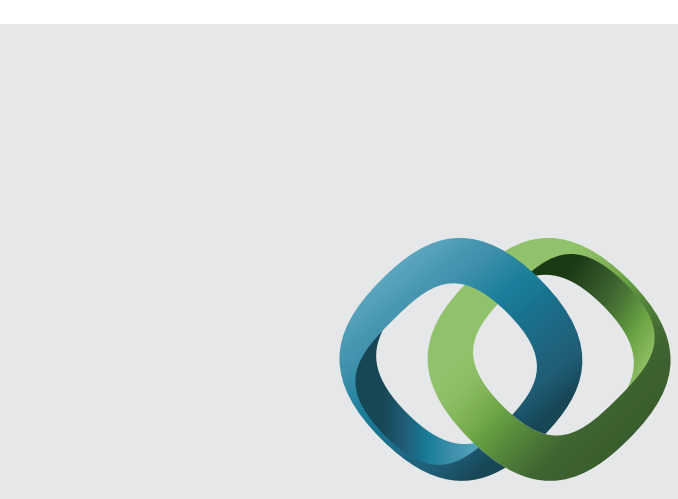

\section{Hindawi}

Submit your manuscripts at

http://www.hindawi.com
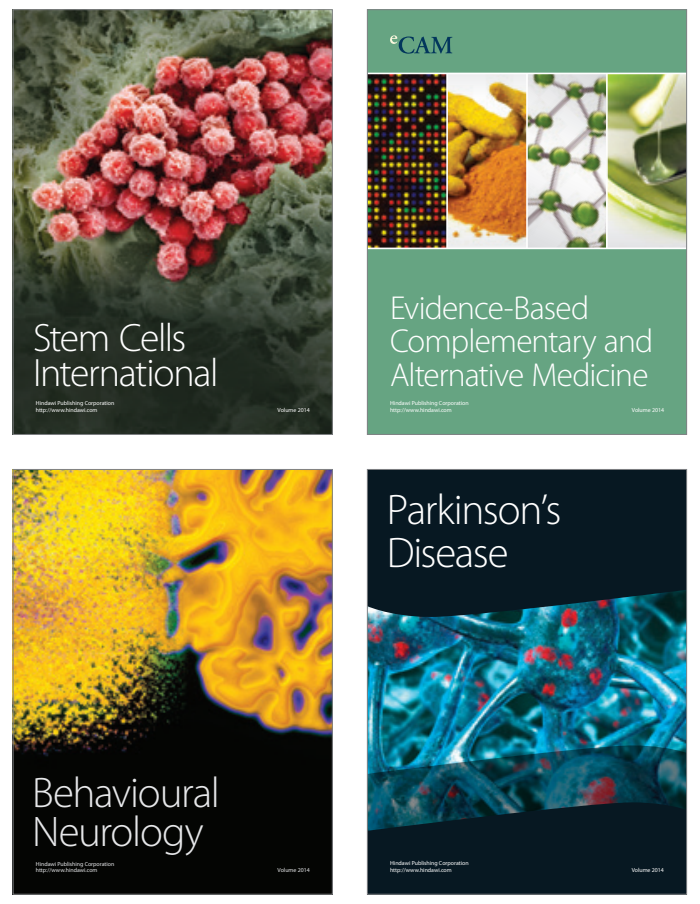
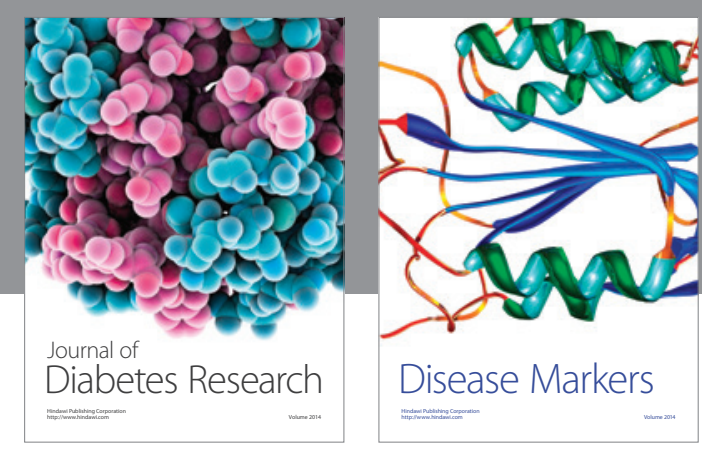

Disease Markers
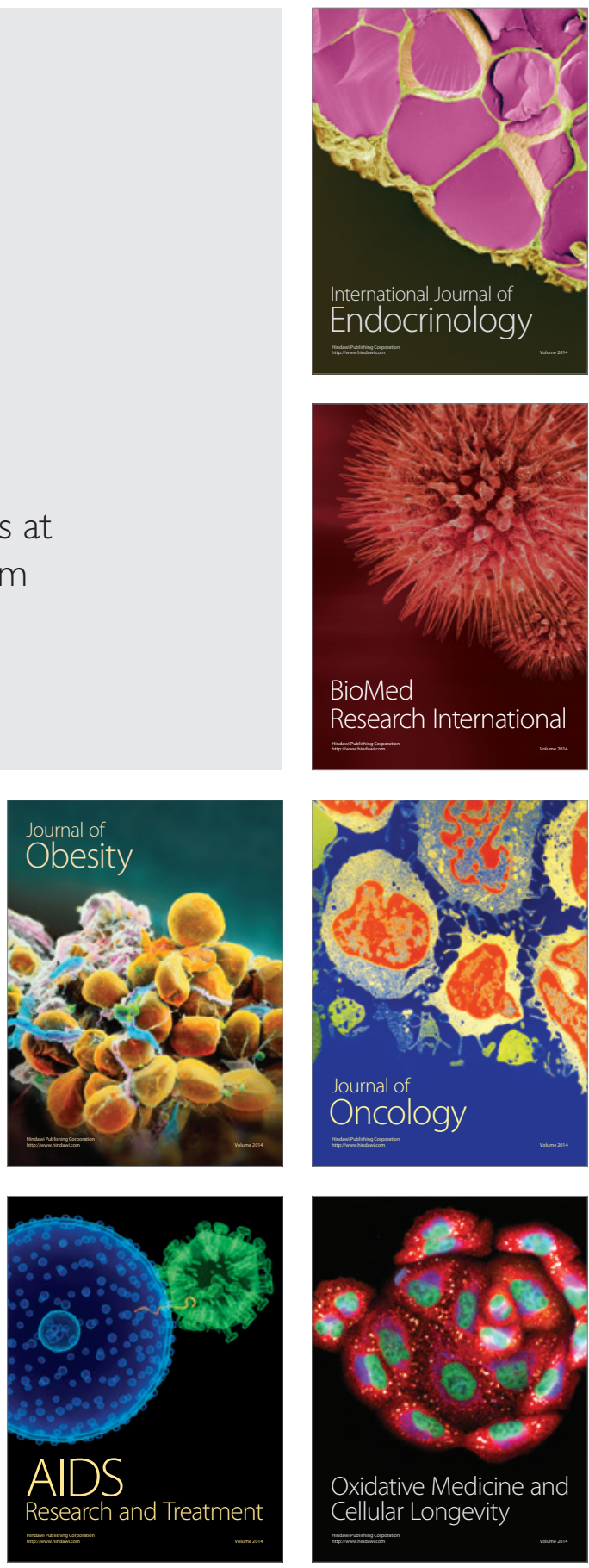